\title{
Città del Vaticano, Biblioteca Apostolica Vaticana, Vat. gr. 573
}

Il codice [mm $290 \times$ 200] consiste di 380 fogli e si compone di sei unità differenti per origine e datazione. La seconda unità trasmette idiografa l'opera Quod optimum

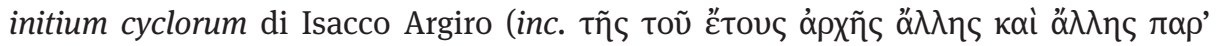

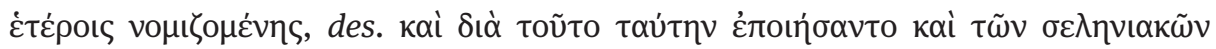

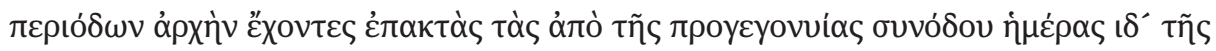

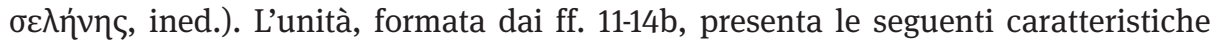
codicologiche: Cart., fil. ff. 11, $14 \mathrm{~b}$ simile a poires (M/Tr nr. 4299, 1353); fasc. $2^{6}(14 \mathrm{~b})$;

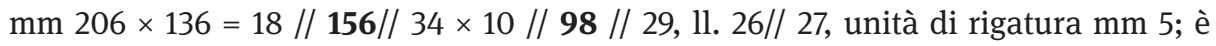
stata vergata interamente da un collaboratore anonimo di Argiro, qui segnalato come Anonimo B. Ad Argiro si devono sette correzioni autografe, tra cui il titolo e due proposizioni di marcato carattere autoriale ai ff. 11r e $14 \mathrm{r}$.

\section{Bibliografia}

\section{Cataloghi}

Devreesse (1937) 469-477.

\section{Studi}

Leurquin (1991) 148. 